University of Wollongong

Research Online

Faculty of Social Sciences - Papers (Archive) Faculty of Arts, Social Sciences \& Humanities

2019

Sharing cities: creating space and practice for new urban agency, capacities and subjectivities

Inka Santala

University of Wollongong, ias998@uowmail.edu.au

Pauline M. McGuirk

University of Wollongong, pmcguirk@uow.edu.au

Follow this and additional works at: https://ro.uow.edu.au/sspapers

Part of the Education Commons, and the Social and Behavioral Sciences Commons

Research Online is the open access institutional repository for the University of Wollongong. For further information contact the UOW Library: research-pubs@uow.edu.au 


\title{
Sharing cities: creating space and practice for new urban agency, capacities and subjectivities
}

\author{
Abstract \\ In recent years, cities across the world have witnessed the emergence of alternative economic practices \\ that have come to challenge norms related to production and consumption. Although a plethora of \\ research has started to emerge on this sharing economy, less attention has been paid to community-led \\ and potentially transformative sharing practices that prioritize peer-to-peer collaboration, equity, and \\ increasing social capital above financial benefits. Following the work of a community-based initiative \\ Share Sydney, this research seeks to understand practices of communal sharing as they emerge in the \\ City of Sydney, Australia. Drawing analysis particularly from the group's Sharing Map project, we explore \\ how communal sharing initiatives like Share Sydney are constituting sharing practice and seeking to \\ develop new kinds of urban agency, capacities, and subjectivities that may feed progressive community \\ development towards more socially just and environmentally sustainable Sharing Cities. \\ Disciplines \\ Education | Social and Behavioral Sciences

\section{Publication Details} \\ Santala, I. \& McGuirk, P. (2019). Sharing cities: creating space and practice for new urban agency, \\ capacities and subjectivities. Community Development, 50 (4), 440-459.
}


Sharing Cities: creating space and practice for new urban agency, capacities and subjectivities

Inka Santala (corresponding author)

University of Wollongong, Australia

School of Geography and Sustainable Communities

ias998@uowmail.edu.au

Pauline $\mathrm{M}^{\mathrm{c}}$ Guirk

University of Wollongong, Australia

School of Geography and Sustainable Communities

\begin{abstract}
In recent years, cities across the world have witnessed the emergence of alternative economic practices that have come to challenge norms related to production and consumption. Although a plethora of research has started to emerge on this sharing economy, less attention has been paid to community-led and potentially transformative sharing practices that prioritize peer-to-peer collaboration, equity, and increasing social capital above financial benefits. Following the work of a community-based initiative Share Sydney, this research seeks to understand practices of communal sharing as they emerge in the City of Sydney, Australia. Drawing analysis particularly from the group's Sharing Map project, we explore how communal sharing initiatives like Share Sydney are constituting sharing practice and seeking to develop new kinds of urban agency, capacities, and subjectivities that may feed progressive community development towards more socially just and environmentally sustainable Sharing Cities.
\end{abstract}

Keywords: Sharing Cities; postcapitalism; agency; capacities; subjectivities

\title{
Introduction
}

Increasing social, environmental, and ethical challenges posed by the dominance of market logics have positioned cities as important testing grounds for alternative economic practice. In opposition to privatization and marketization of the public realm, increasing inequalities, and persistently growing living expenses, communities have started to look for 
more sustainable and communal ways to organize the city and local economies (Foster \& Iaione, 2016). Increasingly, since the beginning of the financial crisis in 2008, a variety of grassroots organizations, for-purpose enterprises and co-operatives have started to emerge, seeking to offer alternatives to the current economic system. Many of these initiatives are utilizing new ways of sharing skills, resources, and services to increase the efficiency and inclusiveness of what they regard as a failing economic system (McLaren \& Agyeman, 2015; Botsman \& Rogers, 2010).

Popular and scholarly debate has emerged on whether sharing can transform competitive and profit-driven economic structures and democratize production and consumption (Burbank, 2014; Frenken \& Schor, 2017; Friedman, 2013; Heinrichs, 2013; The Economist, 2013). Yet, most of the immediate attention has been directed towards the negative and disruptive implications of commercial platforms also labelling their activities as “sharing” (Kalamar, 2013; Murillo, Buckland, \& Val, 2017; Olma, 2014; Srnicek, 2017). This critique of exploitative and precarious dimensions of the "gig" economy ${ }^{1}$, debates around the need to regulate for-profit business-models, and the potential rebound effects of platform capitalism have cast a shadow on more localized and mission-driven forms of communal sharing that have existed for years, side by side with the conventional market economy.

Adopting a language of diverse economies, which understands economic landscape as a "proliferative space of difference" (Gibson-Graham, 2008) that already incorporates multiple forms of economic practice and can preconfigure space for more radical alternatives to capitalist practices, this paper will focus on the community-led and co-produced forms of sharing in urban space and the potential of these practices to transform economic and political organization of the city (Gorenflo, 2017; Sharp \& Ramos, 2018). We hope to develop Loh and Shear's (2015) contribution to this journal on economic alternatives and their potential to feed progressive and more democratic community development in cities. Our analysis is 
framed by the tactic "reading for difference" (Gibson-Graham, 2006, pp. xxxi-xxxii) ${ }^{2}$, as a strategy to make visible alternative economic practices, looking beyond the capitalocentric framings that have dominated the discourses of sharing in the city thus far.

By alternative we mean economic practices that are not necessarily aiming to replace or overtake the capitalist system, but rather work within the current structures seeking to subvert capitalist norms and demonstrate the diversity of economic practices already existing (Chatterton \& Pusey, 2018). We acknowledge communal sharing can be both a cause and response to capitalist production and consumption, often motivated by financial, environmental or social benefits (Böcker \& Meelen, 2017). Thus, rather than asserting that communal sharing rejects the status quo, we explore its potential to transform urban agency, capacities, and subjectivities by offering communities alternative ways to use urban-based skills, spaces, and resources in common, creating a different kind of relation with cities and indeed with capitalism.

The analysis presented in this paper is based upon a case study aimed to understand practices of communal sharing as they are emerging in the City of Sydney, Australia. The wider objective is to shed light on the actually-existing nature of communal sharing and the ways in which these practices might be implicated in reproducing or reshaping dominant urban ideologies and market-encased subjectivities. In this paper, we focus on the work of Share Sydney, a community-based initiative that is aiming to advocate sharing in Sydney.

Drawing on analysis of Share Sydney's Sharing Map project $^{3}$, we explore the complexities, possibilities, and challenges as attempts to nurture communal sharing are activated. The empirical material arises from four months of participant observation in the Sharing Map project as well as interviews conducted with the organization's representatives and city administration during 2018. By documenting the role of actors and their personal motivations, the spaces they provide, and the practices that they have applied, we can begin to 
understand how communal sharing initiatives such as Share Sydney are constituting sharing practice as a participatory social process of commoning and seeking to develop new kinds of urban agency, capacities, and subjectivities that may feed progressive community development towards more socially just and environmentally sustainable Sharing Cities.

\section{Communal sharing as alternative economic practice}

\section{Postcapitalism: Building alternatives from within}

There is growing support for the view that the end of capitalism might be in sight (Gibson-Graham, 1996; Mason, 2016; North \& Cato, 2017). According to Giorgino (2018) much of what is currently disruptive environmentally can be traced back to the normal functioning of capitalist economist system. High production rates with minimal costs and increased material consumption, aimed to achieve financial benefits for the few, have become the assumed standard. Resulting economic pressures have led to resource insufficiency and environmental destruction. Also, the failures of the current system to produce jobs and employment as well as the increasing social inequalities have led to growing criticism of existing norms and profit-driven economic development (Piketty, 2015). ${ }^{4}$

Academic critique of capitalism's social and environmental impacts has often relied on a vision of the economy as fixed, viewed in systemic terms. A powerful counter to this perspective has been developed by the diverse economies research field, which seeks to ground an understanding of the economy as a flexible, co-created and constantly evolving set of relations and practices (Gibson-Graham, Cameron, \& Healy, 2013; Rifkin, 2014). This progressive view brings into debate the possibilities of emerging postcapitalism, achieved by "building alternatives to capitalism within the existing economic system" (Walsh, 2018, p. 48). 
Building alternatives from within demands ontological reframing: reframing understanding of the economy as structured by capitalism to a framing in which the economy is understood as constituted through diverse practices, enacted through multiple instances of ethical decision making. This reframing enables a new understanding of the economic landscape, not as a singular system but as a "proliferative space of difference" (GibsonGraham, 2008). The work of J.K. Gibson-Graham and the Community Economies Collective has been instrumental in this field, paving the way to recognize and acknowledge the diversity of alternative economic practices already existing. As discussed by Loh and Shear (2015), these alternatives are often based on shared values related to social and environmental justice, and they can be seen as hopeful projects that work to demonstrate that "another world is possible" (North \& Cato, 2017). Thus, seeing sharing as an alternative economic practice does not necessarily suggest that it exists to overtake, oppose, or replace existing capitalist structures and norms, but it is rather about "living beyond capitalism" and enacting potential futures in the present (Chatterton \& Pusey, 2018).

Communal sharing can be regarded as looking beyond the profit-driven tendencies of the market economy and its propensity for uneven development in so far as it encourages coproduction, shared consumption, and non-market forms of exchange. These are argued to be forms of economic practice capable of increasing social equality and environmental sustainability, for example, by improving social cohesion and resource efficiency (Heinrichs, 2013). As sharing can provide affordable access without the need for individual ownership (Rifkin, 2014), it has been said to democratize access to goods and services while promoting recycling, reuse, and redistribution of assets, decreasing consumption and the need for new production. In addition, sharing tends to be a communal act (Belk, 2010), and researchers have acknowledged its potential to overcome urban anonymity and generate new social capital (McLaren \& Agyeman, 2015; Botsman \& Rogers, 2010; Davidson \& Infranca, 2016). 
While commercial platforms, like Uber and Airbnb, equally make similar claims, many communal sharing advocates critique such statements as "share-washing" deployed to endorse "business as usual" and continuing to extract profits for a few stakeholders (Kalamar, 2013; Sharp, 2018; Srnicek, 2017). Hence, only when viewed through the prism of the communal can sharing be positioned as an alternative economic practice and as part of the participatory and postcapitalist new economy.

\section{Communal sharing co-creating the city as a commons}

In this paper, we define communal sharing as community-based sharing initiatives and practices that are run by and predominantly for local residents and do not concentrate on creating financial profit for a few shareholders. Our definition focuses on initiatives in which the value generated is distributed widely, back to the local community and to those involved in the co-production process. ${ }^{5}$ Community ownership (Martiskainen, 2017) and the aspiration to respond to local needs are crucial. They suggest new kinds of urban agency, as participants strive to become more self-organized, emancipatory, and resilient (Seyfang \& Smith, 2007). Communal sharing rejects the view that resources and services should be provided top-down. Instead, it highlights the role of local communities in taking collective action for the common good. In this way, communal sharing can also be seen to connect with the commons movement and aims to reclaim and create new shared capacities (Foster, 2011; Iaione, 2016).

Throughout history, commons have been understood as material and open access resources that need to be controlled in order to avoid exploitation and overconsumption (Hardin, 1968; Ostrom, 1990). Yet, more recently a growing body of research has emerged that seeks to understand commons as more than property, through the social relations and structures that produce them (Euler, 2018; Gibson-Graham, Cameron, \& Healy, 2016; Williams, 2018). What this means in terms of cities is that, instead of focusing on urban commons as something that is profoundly place-based and physically defined, commons can 
be re-thought as resources and capacities that are co-created, through the collective efforts of city residents (Huron, 2015).

Moving from a subject—commons— — to a verb—“commoning” (Bollier, 2014)— introduces a process and set of practices that can be understood as citizens' collaborative production of the city itself (Foster \& Iaione, 2016). Indeed, communal sharing can be conceived as a participatory social process of commoning, co-creating, and reproducing the shared spaces, resources, and services that can be regarded as urban commons: commons as performed into being through practice (Williams, 2018) and commons as always in a state of becoming (Gibson-Graham et al., 2016; McFarlane, 2011).

Understanding communal sharing as the collective production of new urban commons, changes the way sharing practices might be perceived and conceptualized. It suggests the potential for a new kind of urban agency that expands citizens' subjectivities from passive consumers into active collaborators, creators, and co-producers of the city's shared capacities (Iaione, 2016). No longer do people only inhabit roles posed by hegemonic structures of capitalist economies, such as user or consumer (Colling, Stovall, Flaherty, Cope, \& Brown, 2017), but they can also begin to identify alternative, more ethical and social roles such as collaborator, gift-giver, volunteer, and potential change-maker (Gibson-Graham, 2006).

According to sharing advocates, these alternative practices of communal sharing in the city demonstrate citizens' capability to self-organize and to build healthier local economies that rely on shared values and collaboration (Llewellyn \& Gorenflo, 2016). In advocates' view, not only are these sharing practices creating new capacities for local communities, but they can also be regarded as attempts to build new understandings of the city itself as a commons (Foster \& Iaione, 2016), co-created and managed through collective action in urban communities (McLaren \& Agyeman, 2016). This idea of a Sharing City means seeing the city as a shared resource, belonging to and remaining inclusive to all city inhabitants (Foster \& 
Iaione, 2016; McLaren \& Agyeman, 2016). As an ideal, the Sharing City is based on pragmatic, community-based solutions that are implemented to address common needs. Advocates recognize, however, that no one-size-fits-all solution or Sharing City formula is possible. Rather, experimentation, collective learning, and iteration are intrinsic to the Sharing City (Gorenflo, 2017).

Many Sharing City advocates promote more intensive facilitation of emergent communal sharing initiatives to meet the needs of the citizens and build new capacities across the city (McLaren \& Agyeman, 2016). However, to date there is not much research into how this process evolves or what kind of agency, capacities, and subjectivities communal sharing can nurture. This paper aims to provide insights into this process, exploring the actuallyexisting practices of Share Sydney as it aims to facilitate communal sharing in the City of Sydney.

\section{Case study of Share Sydney}

\section{Background and methods}

One of the biggest promoters of the global Sharing Cities movement has been the news and collaboration hub Shareable. In 2013, Shareable launched a global Sharing Cities Network $^{6}$ and has since been advocating for community members to self-organize and mobilize to run series of collaborative mapping events. The aim of these MapJam events has been to make shared community resources visible and to help local stakeholders build a stronger sense of community (Luna, 2013; Maclurcan, 2012). Today over 70 cities have joined the global Sharing Cities movement and mapped the city's shared resources and services (see Shareable, 2018).

Inspired by this global movement and wanting to create a local resource for Sydney, Australia, a group of like-minded individuals came up with a project plan and started the 
Share Sydney collective. This informal, bottom-up initiative consists of local advocates coming from various backgrounds in arts, media, education and community organization - all united by interest in the sharing economy and the ways it might be harnessed to support progressive community development. The aim of Share Sydney was to create Sydney's first Sharing Map and help to educate city residents on how they could share more and become active members of a collaborative and healthy new economy (The Sharing Map, 2018). To realize the project plan, Share Sydney applied for and received a community services grant from the City of Sydney local government.

The City of Sydney is one of the 40 local governments that make up the greater Sydney metropolitan area. Including the city's central business district and surrounding inner city neighborhoods, it is considered to be the key economic driver of the Sydney region (McNeill, Dowling, \& Fagan, 2005). Community projects funded by the local government are often restricted to single sites within the jurisdiction. However, to increase community engagement with the Sharing Map, it was planned that the project would take place in four different neighborhoods within the local government area: Glebe, Ultimo, Woolloomooloo and Green Square. In general, these are ethnically mixed though largely well-off inner suburbs. Glebe and Woolloomooloo are long established, Ultimo is a former industrial suburb that was regenerated in the 1990s, while Green Square is a more recently redeveloped area, also with an industrial past. The aim to capture at least some facets of social diversity was well-described by one member of Share Sydney:

The idea was that we did [the project] in four different parts of the City of Sydney. The rationale for that was that we connected with those different communities ... So Glebe, you know, was maybe middle-upper class sort of [area]. Woolloomooloo was a very diverse range of people. Green Square was 
people who were really new to Sydney or were maybe living in an apartment building. So the idea was to work with different members of the community. The analysis presented here is based on four months of participant observation during the execution of the Sharing Map project, plus supporting interviews with Share Sydney members, two additional volunteers, and City of Sydney councilor. We do not seek to provide an evaluation of the work of Share Sydney, but rather to begin to understand how the actors, the spaces they provide, and the practices they have developed might be implicated in (re)shaping economic agency and capacities as well as other than market-encased subjectivities. The participant observation enabled a close documentation of the practices of nurturing communal sharing, while research interviews helped to clarify the findings and offered new perspectives on the work of Share Sydney. Together, qualitative research methods made it possible to explore and understand the moments, spaces, and practices that are seeking to generate communal sharing as the participatory social process of commoning in the City of Sydney.

\section{The Sharing Map project}

With support from the local government, Share Sydney initiated the Sharing Map project in 2017. The project consisted of a MapJam event ${ }^{7}$ and four community workshops across the local government area, aiming to reveal and facilitate access to the city's shared resources and strengthen the local sharing economy.

The MapJam was held on the $1^{\text {st }}$ of March 2018, and it attracted around 60 participants from various backgrounds including residents, city administration, academia, and the business and community sector. Although similar mapping events have been held in cities across the globe and in other parts of Australia, this was first of its kind in Sydney. There is no established way of doing a MapJam, although several tips and suggestions have been provided for cities by the transnational news network of Shareable (see e.g. Llewellyn, 2016). 
Sydney's first MapJam consisted of one hour of collaborative mapping, followed by two different games aimed to provoke people's thinking and familiarize them with sharing, speeches from a City of Sydney councilor and the editors of Shareable $e^{8}$, as well as opportunities for social networking.

In the collaborative mapping phase, participants were divided into five different mapping stations each with a particular theme, including "spaces", "stuff", "food", "skills" and "transport". First, the facilitator gave participants some instructions and prompts to inspire and trigger their memory about theme-related sharing opportunities. Then people discussed and shared their knowledge about different sharing initiatives and projects they were familiar with in the city. These were then recorded on listing cards and passed on to volunteers who entered them into the online map database. At each station participants had about 10 minutes to list all their suggestions, before moving to the next station. In addition to these mapping stations, there was also one visioning station, in which participants were provoked to think about possibilities and challenges for sharing space, skills, and resources in the City of Sydney towards 2030.

The second phase of the MapJam involved a game activity. Participants could choose between two interactive games depending on their status and interest. The Share City game was developed for participants that represented an organization or community project. The game aimed to reveal future collaboration opportunities for the sharing initiatives in the form of an "offers and needs market". ${ }^{9}$ The second game, Share Street, was developed for participants that were more interested in looking at their own personal sharing capacities. In Share Street participants were divided into "households" of five to six people, each with a designated mission that they needed to accomplish by swapping their skills and resources with other households. After the games, all the participants were gathered together for the 
unveiling of the co-produced Sharing Map and were invited to take part in the upcoming community workshops.

The community workshops were facilitated in the neighborhoods of Glebe, Ultimo, Woolloomooloo and Green Square to take advantage of the synergies and collaborations created at the MapJam. The workshops included storytelling, repetition of the Share Street game, presentation of the Sharing Map, and collaborative brainstorming for potential sharing initiatives that were still missing from the online database. The detail of each workshop varied depending on the audience, facilitators present, and space in which the workshop was held.

\section{Analysis}

\section{(Re) constructing agency, capacities and subjectivities in the city}

Now we turn to explore the practices of Share Sydney as it advocates communal sharing. Adopting the epistemological practice of "reading for difference" we aim to make visible the moments, spaces, and practices which might have the potential to nurture new economic agency, capacities, and other than market-encased subjectivities in the city.

Taking inspiration from the postcapitalist political imaginary, nurtured by GibsonGraham (2006), we define agency in this context as actors' ability to see alternatives to the current economic system and willingness to regard communal sharing as one viable alternative. On the other hand, we use the term capacity when referring to actors' ability to take part in the alternative economic practices and to act according to their values (Laverack, 2005; Matarrita-Cascante, Trejos, Qin, Joo, \& Debner, 2017). We understand subjectivity as a socially constructed subject position that is not given but constantly evolving (Probyn, 2003). Although we have divided the analysis section to discuss each of these aspects separately, we recognize their deep and complex inter-relation. 
In the conventional market economy, individuals can be seen to have quite limited economic agency when it comes to their behavior and decision-making (Colling et al., 2017). This is mainly due to the constrained subject positions available to be identified with (including user, producer, consumer, worker, or entrepreneur). Many times, these subject positions are seen as explicit and all encompassing, although it can clearly be argued that all individuals have multiple subject positions and subjectivity is never fixed but constantly evolving and produced through social structures and discourses (Probyn, 2003).

Rather than suggest a set of possible alternative economic subjectivities, the work of Gibson-Graham (2006) brings out an additional set of social identities such as a volunteer, gift-giver, community worker, social entrepreneur, co-operator that can be identified beyond the more conventional ones. Although there is no single term for these alternative subjectivities, they largely exist outside the dominant framework of the current economic system. This has prompted us to use the language of diverse economies to explore the various forms of subjectivities that might be identified through the practices of communal sharing.

Understanding subjectivity as produced and evolving, we acknowledge identities arise through repeated performances which, in turn, offer possibilities for variation and change. A change in the subject position and personal economic agency is likely to happen when individuals recognize different opportunities and decide to make a change, so become willing to act upon alternative aspirations. According to Gibson-Graham (2006, p. 77) "a counterhegemonic politics involves dis-identification with the subject positions offered by a hegemonic discourse and identification with alternative and politically enabling positions." This process of (re)constructing subject positions includes multiple complex stages, which can be simplified as: identifying the alternative subject position, exploring the subject position through practice and developing new personal aspirations in line with the sense of this alternative economic subjectivity. 
The process of subjectification can be challenging as a person is caught between two, potentially controversial positions: one of which the person is dissatisfied with but can relate to due to habitual practices, and one of which the person finds new and interesting, yet difficult to determine and desire. Here Gibson-Graham (2007) argue that the individual needs encouragement to adopt an alternative subject position. In this paper, we acknowledge the role of Share Sydney as an important middle actor, aiming to bring around social change, not only by identifying alternative subject positions but also by helping people to gain new kinds of agency and capacities to live life according to their values.

In what follows, we theorize the conditions of possibility associated with communal sharing practices rather than challenges. Although challenges and potential controversies will be covered as part of the broader case study, a question guiding our analysis in this paper can be articulated as follows: How is the potential of Share Sydney to create new economic agency and capacities as well as other than market-encased subjectivities taking shape in the City of Sydney? We start answering this question by working through each category: agency, capacities, and subjectivities, drawing out brief examples to illustrate.

\section{The practice of collaborative mapping: Introducing new kinds of economic agency}

In this section we discuss the collaborative mapping process and its potential to impact participants' ability to see alternatives to the current economic system and willingness to regard communal sharing as one viable alternative.

Firstly, in order for a person to have the ability and willingness to recognize alternatives, the individual needs to find space for improvement within the existing economic system. Often the willingness to look for change arises from dissatisfaction and frustration with the current state of affairs (Walsh, 2018) potentially associated with the growing critique of the existing economic system (Mason, 2016; Piketty, 2015), which suggests there might be a fertile soil for new ideas and responsive agency to occur. 
What became clear in the early stages of the research project was that, among sharing advocates, the practices of sharing and co-production are often seen to provide practical solutions and a sense of agency to act upon immediate social challenges. For advocates, sharing presented a means by which individuals are empowered to start contributing towards practical solutions. This move prompts a recognition that change is possible even if it had first seemed too major or difficult to tackle by themselves. As one Share Sydney volunteer put it:

So you think about how do you solve something like climate change, or how do you solve sustainability. And sharing suddenly becomes a way in which, suddenly, the individual has agency to actually begin making decisions on those issues: so, choosing to not consume resources in a traditional way and instead to share, and share access over individual ownership. Suddenly the individual is given a way in which they can actually make a decision to act upon solutions to a problem that, without this idea, can often be seen as larger than the individual. Both sharing advocates and city representatives interviewed highlighted the possibilities of the sharing movement to create new social connections and envisage alternatives: key dimensions of agency. The potential of Share Sydney to generate such agency around resilience was strongly asserted by one of the initiatives' champions, a City of Sydney councilor:

The wonderful thing about the sharing movement - "sharing movement" is better than "sharing economy" because it's not just about economy-it's that it hits so many of our goals. You know, one of our key goals is to create resilience and, for us, the resilience is both in being able to adapt to environmental changes and challenges ... but also resilience comes about by having networks and by having social networks and having a sense of connection and having alternatives. And for 
us, I think something like Share Sydney helps us achieve both of those goals in a really beneficial way.

Considering the MapJam event, collaborative mapping created a suitable, enabling environment for nurturing new kinds of agency as most of the people demonstrated a readiness and willingness to look for change and new alternative ways of being in the city, by joining the event. These were community members who had already identified problems within the current economic system and had potentially heard about or even taken part in some of the sharing practices, as noted by a member of Share Sydney:

It felt to me during the night that people, most people who were there, had some, at least some idea of what the sharing economy was about, and it wasn't a strange or new thing to them. They were quite open and accepting of it. And, obviously you need those people, because they are the ones who know about the sharing initiatives.

By bringing these like-minded people together and physically gathering them around themed tables to discuss alternative options, Share Sydney managed to create a space of synergies where people felt more comfortable and empowered to have their voices heard. Realizing the collectiveness, ideas from one participant would spark up new realizations among others, and one eager participant was able to get several others more engaged with the task at hand. The role of communication and cooperation is also noted by Matarrita-Cascante et al. (2017), who argue that community agency should be seen as ongoing social process where people work together to accomplish a local goal. As a volunteer of Share Sydney phrased it, the process of collaborative mapping became a way for people to "put ideas into an organized voice." The open and welcoming atmosphere, as well as discussions facilitated by the members, enabled local actors to take an active role not only as participants but as co- 
creators of the Sharing Map. This can be demonstrated through a discussion observed in one of the mapping stations:

Hey what about the community garden near the library? -Yeah, I have heard there is an active group who does lots of other things as well, like skill sharing, helping people to fix things by themselves. - Like that repair café at Addison Street? -Oh, that definitely needs to be on the map!

Yet, in addition to the desire for change, an individual needs to be aware of the opportunities available to spark new kinds of agency. This means not only demonstrating new behaviors and habits but also making these seem viable and reasonable alternatives to old practices and manners. It is here that the process of co-creation becomes important (Martiskainen, 2017; Sharp \& Ramos, 2018). According to Sharp and Ramos (2018) co-production of the city through asset mapping can help individuals to see new, previously hidden or weak possibilities as more viable options, making alternative aspects of city life more "visible and tangible" (Manzini, 2015, p. 121). For example, in initial activity at the mapping stations it was clear some participants were skeptical about sharing practices especially when it came to the local context, questioning whether there would be anything worth mapping in Sydney. However, after they participated in the mapping process and saw the map coming together, several participants came forward saying they were amazed to see how much sharing there was already happening in the city and that they now understood it was not just something happening elsewhere but could be connected with locally. This was also articulated by one of the Share Sydney volunteers:

Before I started, I didn't really have much experience with the sharing economy apart from either just sharing personally with people that I know or kind of the other end of the spectrum using big established platforms like Airbnb and Uber and things like that... not only did it sort of open my eyes to those bigger 
companies and who's actually benefiting but it sort of took away the barrier to start sharing. I'm finding that when you start to look around there's so many ways that you can get involved.

As Thorpe (2018) has argued, the process of participation is crucial as it not only gives effect to alternative understandings of what could be but also helps individuals to self-identify those ideas. This self-realization was demonstrated in the MapJam in the way participants were able to debate and discuss which initiatives should be in the map and what should be left out. These discussions helped the participants to identify practices and behaviors that already existed in the city and reflect on their role when considering the "business-as-usual". The process of co-creation and collective decision-making helped to create a sense of ownership around the project. According to Thorpe (2018, p. 100) these "understandings of ownership play an important role in determining whether and how people feel able to act to (re)shape the city". In the case of the Sydney MapJam, the process of collaborative mapping helped participants to view city space and resources as flexible and negotiated, rather than something firm and fixed from above. The importance of this bottom-up approach was also recognized by the City of Sydney councilor:

I think these things are more useful and meaningful when they're actually driven by the community and when they come from a community desire and a need, because it actually takes people's time and energy and personal networks to make these things work. You know, if the city comes along and says: "Here is a toy library, or a community garden," and then kind of pushes it on people to: "Okay, now you run it." I don't really think that will have the kind of longevity or life or resilience that a project that was driven by the community would have. I think it's about supporting bottom-up rather than enforcing a top-down approach. 
Allowing people to contribute to the creation of the map, Share Sydney helped local communities to identify alternative economic practices and made them seem more approachable and accessible. In this way, people also became more familiar with working together and building collective agency to pursue a city as a commons. Through repetition and low threshold activities Share Sydney could be said to be helping participants to create a sense of mutuality and normality, which is regarded to be crucial for these kinds of urban transformation projects (Radywyl \& Biggs, 2013).

\section{The Sharing Map as an enabler, creating new capacities for the city}

If the ability to see alternatives to the current economic system and a willingness to take part in these activities can be cultivated how, then, can these desires be enacted in practice? In what follows, we explore the role of the Sharing Map as a potential enabler, making it possible for people to act according to their values and to take part in alternative economic practices within the existing economic system.

To begin with, taking part in alternative economic practices such as communal sharing depends on the fact that the person is informed about these alternatives and can view them as viable alternatives to their current practice. In addition, there needs to be some supporting structures and an open atmosphere for this activity to take place. In this regard, there must be opportunities for the person to change their habits and behavior. The Sharing Map can be viewed as a valuable resource, making alternative economic practices more visible and enabling people to take part in these activities, as noted by a volunteer working for Share Sydney:

I still think [sharing] is marginal because it is not the sort of normal expectation. It is not the clothes that people put on before thinking. To people now, to decide to share, it is not an unconscious normal behavior of "here is the problem, here is of course how I will solve it." The way that people do that now is that "I have a 
problem, I go to the shops and you know do a professional transaction. That is how I am going to solve it." And so, people do that without even thinking. So, trying to get people to change that behavior that is the toughest bit. To get them to try a new outfit they are not used to do, that they are not comfortable with, that they do not know how it fits - is going to be the toughest bit. And I like to think that if you can actually get through that really, that conscious decision process and have infrastructure developed in which it comes more normal. Then it becomes much easier to achieve. And I think the Sharing Map can help make that transition easier.

Co-produced in the MapJam event and moderated by the members of Share Sydney, the Sharing Map is a publicly available online database that includes all the sharing initiatives and projects that can be regarded as alternative. Alternative, in this case, means missiondriven sharing initiatives that do not rely on creating financial benefits for a few shareholders but instead aim to distribute the benefits back to the local community. Although most of the initiatives were mapped by the participants in the MapJam event and community workshops, Share Sydney constantly moderates the Sharing Map by adding new suggestions and correcting information when necessary. For advocates, it is not only about creating awareness but also about developing community structures and habituation that help normalize sharing practices. As one member of Share Sydney put it:

We are doing this to heighten the awareness of the sharing economy in Sydney, and maybe further afield, I suppose. So, in that sense, it's an awareness building thing. But related to the awareness building thing, for me, is the community development aspect. So, when more people get to learn about it and feel more comfortable with it, they'll hopefully do it more. For me, in a nutshell, that's probably what it's about. 
The Sharing Map creates new capacities for the city, in the sense that it offers a practical way for community members and city residents to learn more about communal sharing and take part in these activities. Through the online database people can search for sharing initiatives near them, whether it is shared spaces, skills, or resources such as men's sheds, toy libraries, or community gardens. The Sharing Map builds awareness of and demonstrates the existence of these shared resources and services. In addition, it provides community members with an opportunity to review the city and their role in it. Through the online map, the city becomes something more approachable and inclusive, something that residents can interact with. As explained by a member of Share Sydney in the promotional video:

What we found was that a lot of people would know about one thing or another, like a, you know, one of those little book libraries or they would know about a community garden, but they would not realize how many different things there were in all the different areas. And how many there are and they did not know where they were in their neighborhood. So, we got a map now, they can just log on, have a look at the map. They can go to the section that they are interested in, if they want toys for their kids, they can find toy libraries. They can find one close to them. So, it's just a way we can all pitch in. 'Cos we have actually made it so that they can add new sharing things as well. So, we got about 150 at the moment, but we are thinking we will probably get into 300 or... who knows. People just keep making up these cool new ways to swap and share. It is fantastic! (Filmed by Sherman Lo, the video can be accessed through https://thesharingmap.com.au/). The Sharing Map provides a resource that helps people to rethink the city as a shared resource and enact fledgling desires for a postcapitalist economy by giving people opportunities to change their habitual behaviors and practices. Share Sydney's co-produced 
map declares to citizens of Sydney that this city is a shared space. By facilitating engagement with the sites identified on the map, Share Sydney provides spaces of opportunity for people to become involved and to change their current practices, enacting alternative economies. A volunteer of Share Sydney highlighted the role of the Sharing Map as providing a low-key entry point to normalize practices of sharing:

Suddenly, having these online resources, an asset map, the requirement to entry becomes less. You, anyone, can use this website and find a solution to a problem without having to have been ... heavily committed to it. Suddenly, it is more accessible and can reach a wider audience in which case hopefully these behaviors and networks can become more normalized.

As much as the Sharing Map is about normalizing sharing behaviors and increasing accessibility, it is also about community organization and self-management. Instead of the city administration or other institutions imposing structures and norms from above, the Sharing Map is about city residents coming together and co-creating new social rules and practices. The website is not a guidebook to sharing, but rather a demonstration of possibilities already existing, encouraging people to become involved and create their own alternatives. As one Share Sydney member noted:

The Sharing Map is an example of a local community—grassroots up — because it's... there's no organization that is saying: "This is what, you go and share with that." It's getting everyone to do it themselves. Everyone to organize themselves ... The Sharing Map is trying to show, once again, that things are already happening. It's trying to almost amplify what's already going on as opposed to saying: "This is how you share, everyone."

Enabling people to engage with the city in material and relational ways is crucial in developing a sense of city as a commons, managed and co-created through collective effort of 
its inhabitants. Through the Sharing Map, the city becomes something more collaborative that can be worked with creatively.

\section{Identifying alternative subject positions through the sharing game}

Finally, how can these actions impact the way people perceive themselves and their role in the city? Here we focus on the potential of the Share Street game in helping participants to identify alternative subject positions and extend their understanding of their own economic subjectivity. Understanding subjectivity not as predetermined, but as a process and an outcome of social production (Probyn, 2003), allows us to consider how it can evolve and be redefined through practice. Taking the subjectification process to involve multiple and complex stages of identification, practical exploration, and development of new personal aspirations (Gibson-Graham, 2006), we consider the practices of Share Sydney to make visible the moments, spaces, and practices through which this (re)configuration might take place.

Part of what made the Share Street game interesting was the way it invited participants to reposition themselves in the local economy by rethinking issues related to ownership and consumption. Firstly, as the participants became involved and decided to play along, they stepped into this alternative scenario where they needed to reframe themselves as part of an imaginary household along the Share Street. Here they had their own possessions and skills but soon learned that these would only be used as a common resource base for their collective household, and they were forced to swap these in order to complete a common mission. This part of the game helped participants to recognize the skills and resources that they had and encouraged them to change their attitude and relationship with these personal capacities. No longer could they be attached to these individual goods, but they were forced to think collectively and innovatively about these. One Share Sydney member reflected: 
Sometimes people love the idea but they don't... they can't think of what to offer or what they want. So, [the game] is a great way for people to brainstorm offers and wants.

Once households were given their designated collective mission in the game- for instance, "build a community garden" or "organize a family camping trip" - they needed to create a common strategy and work with other households to swap their skills and resources. What surprised the game facilitators was that, when the participants were forced to swap and let go of their traditional ideas on ownership and individuality, they ended up sharing even more than they had to and found very creative ways to complete the mission. As mentioned by a Share Sydney volunteer:

I think, when I first heard about the game I did not really think that it would be as creative and as successful and as fun as it was. Everyone really kind of jumped in. I think because it was kind of a hypothetical sharing situation, you know, there was no hesitation to put up things for sharing and there was no risk involved so people were sharing everything and anything.

People also brought their personal lives to the game by explaining that actually the car that they had to swap was a bit rusty and not really good on the dirt roads but would probably be enough to transport stuff from the neighborhood household to the market place that they needed; or that they were actually really competent with tools so could come to help out constructing the garden beds for the other households' community garden. This helped the participants to recognize their own subject position, while prompting ways to extend that.

Some participants resisted the narrow and profit-oriented game design and started creating their own rules for the household sharing. Not only were they swapping resources and services as token-for-a-token, but pushing beyond the rules of the game, they also used the existing modes of borrowing, lending, giving, and bartering to complete their challenge. 
For instance, when it came time for the "transaction" one participant said: "Actually, we do not want to give these pillows to you, but we can lend them. If you use them on Wednesday at your market stall, we can take them back on Thursday for our camping trip." And later another participant was also observed doing similar agreements: "I can volunteer at your community garden, if you come to help us with the marketing for our street fair."

Suddenly, the pre-given mission of a family camping trip merged into a scout camp with local volunteers cooking the food, and the community garden became not just a garden but a place for the whole community to come together and be creative, for example, by fixing things and sharing skills with each other. These practices enabled participants to identify themselves not only through the existing economic subject positions as owners and users of common resources but also recognize the multiple other subject positions that they could inhabit, as volunteers, gift-givers, co-creators, and potential change-makers. By creating their own rules and bringing in existing forms of sharing, the participants had the opportunity to reframe themselves and trial new behaviors and alternative economic practices that already existed in the city. As explained by a volunteer of Share Sydney:

In the Share Street you ....as an individual became more important than the transaction, and it was all about what can I give... Often in theory it sounds quite difficult to stop, not just buying something, but instead to share. It sounds really tough. It sounds awkward. And then you go and do it and you go like "that was great!" I met someone, or I met a few people and I had things to offer and we got to talk and I made new friends and new opportunities would come up and I felt very empowered and excited. And it is not until you've done it that you understand that. So I think Share Street is a really good way for people to get that experience and to get that hunger of: "that is very cool!" 
The game seemed to present a new kind of economic subjectivity that was concerned for and connected to others. People also got the chance to encounter themselves differently. By taking people out of their usual comfort zone and introducing them to new ways of thinking and doing in a playful form, it was easier for people to try out new kinds of roles and behaviors, overcoming existing and sometimes sticky subject positions. The game became a communal space where participants were able to re-narrativize themselves as part of this diverse, alternative economy and reconstruct their subject position in the process. The potential of sharing to open up more active and empowered subject positions was also recognized by the City of Sydney councilor who considers it:

...a way for people to feel more empowered and to feel more entitled to shape the city in a way that reflects their values and their needs. I think, a lot of the time, we feel like someone else designed the city and we just live in it and participating in the sharing movement, and particularly that sharing movement having an impact in public space, makes you feel like you're actually making your mark in a place and that you're entitled to do that.

Taking part in the sharing game, the participants held multiple subject positions at once. They were employees, entrepreneurs, retirees, students, users, and consumers, yet simultaneously, they inhabited a set of new identities that they had practiced during the game as a community member, gift-giver, volunteer, co-creator, and change-maker. This gave them an opportunity, at least temporarily, to transform the mentality from consumer and user to active co-creator and producer of the city as a shared entity. In a way, the Share Street game worked as a process of destabilizing existing identities, prompting new identifications and cultivating different desires and capacities. As identities arise through repeated performances (Dewsbury \& Bissell, 2015), this opens possibilities for variation and change. 


\section{Conclusion}

This paper has explored communal sharing as an alternative economic practice and used the tactic of "reading for difference" to make visible the moments, spaces, and practices that might help nurture new economic agency, capacities, and other than market-encased subjectivities in the city. By documenting the actually-existing practices of communal sharing that took place during the Sharing Map project, we started to understand how initiatives like Share Sydney are encouraging new ways of doing, thinking, and being in the city (see Williams, 2018). The practice of collaborative mapping brought together Sydney residents to work on a common project, demonstrating a process of commoning that created a shared resource for the city in a form of the Sharing Map. This online database not only brings visibility to the alternative practices already existing but provides people an opportunity to reenvisage the city as a shared space. In addition, the Share Street game provided an opportunity to test new roles and behaviors, contributing spaces and moments in which new subjectivities might arise. And while this paper has drawn on a case study of the primarily prosperous and privileged context of the City of Sydney there are, nonetheless, learnings that can be sensitively extrapolated to other communal sharing contexts.

As Chatterton and Pusey (2018) point out, these alternative practices of postcapitalism will not necessarily form a systematic wave of social change. However, in presenting "useful forms of doing" and producing, practices like communal sharing have the opportunity to support progressive community development, fostering relations of care, social connection, and community empowerment (Chatterton \& Pusey, 2018, p. 11). They can be seen as important testing grounds for alternative economic practices, helping urban communities to craft new understandings of agency, develop new forms of capacity and inhabit new subjectivities that can extend beyond the time-spaces of the initiative itself. Thus, even if temporary manifestations such as Share Sydney do not necessarily enact long-term solutions, 
they can provide spaces that, through their nurturing of alternative agency, capacities, and subjectivities, can make visible and habitual the practice of new economic norms: a form of preconfiguring postcapitalist futures in the present.

\section{Notes}

1. By "gig" economy, we refer to the commercial peer-to-peer platforms providing an ondemand workforce. The gig economy has been associated with problems related to precariousness, workers' rights, and safety (see Ravenelle, 2017)

2. This re-reading practice stems from feminism and queer theory adopted by Gibson-Graham in their aim "to uncover or excavate the possible" (Gibson-Graham, 2008, p. 623). As an epistemological approach, it has been applied in several studies wanting to look for morethan-neoliberal practices and non-capitalist constructions of society (see e.g. Diprose, 2017; Harris, 2009; May \& Cloke, 2014; McGuirk \& Dowling, 2009).

3. See http://thesharingmap.com.au/

4. While a comprehensive review of neoliberalist and capitalist critique is beyond the scope of this article, we want to acknowledge the proliferation of literature concerning these issues (Harvey, 2005; Klein, 2014; Rifkin, 2014; Rossi, 2017). This literature urges us to look beyond capitalocentric framings of current urban development and examine the countermovements already existing.

5. Definition inspired by Sharon Ede's Taxonomy of the Collaborative Economy, https://docs.google.com/document/d/1FhvZqBX05_-J9UDjdj6bewLx2duq1bbDpisGrJNRE/edit

6. The Sharing Cities Network connects local sharing activists in cities around the world for fun, mutual support, and movement building, https://www.shareable.net/sharing-cities-network

7. According to Llewellyn (2016) a MapJam is "an easy-to-organize event where a small, dedicated group of people get together for a few hours to map as many sharing services in their city or town as possible. Like a music jam, it should be fun, social, and interactive."

8. Listen to Shareable founder, Neal Gorenflo's greetings to Share Sydney from https://www.youtube.com/watch?v=czFKXh-QnkA

9. An "offers and needs market" is a participatory activity that seeks to realize potential collaborations and create new connections. Like a traditional market place, the aim is to meet participants' needs with other participants' offers, yet it is based on the sharing of skills, time, or resources and does not include monetary transactions. 


\section{Acknowledgements}

We would like to thank the editor and two anonymous reviewers for their helpful comments.

We also appreciate feedback received at the 5th Global Conference on Economic Geography in Cologne and New Economy Conference in Melbourne to earlier drafts of this paper. Thank you also to all research participants, namely the members of Share Sydney who welcomed us to be part of their Sharing Map project.

\section{Disclosure statement}

No potential conflict of interest was reported by the authors.

\section{References}

Belk, R. (2010). Sharing. Journal of Consumer Research, 36(5), 715-734. doi:10.1086/612649

Böcker, L., \& Meelen, T. (2017). Sharing for people, planet or profit? Analysing motivations for intended sharing economy participation. Environmental Innovation and Societal Transitions, 23, 28-39. doi:10.1016/j.eist.2016.09.004

Bollier, D. (2014). Think like a commoner: A short introduction to the life of the commons. Gabriola Island: New Society Publishers.

Botsman, R., \& Rogers, R. (2010). What's mine is yours: How collaborative consumption is changing the way we live (1st ed.). New York: HarperBusiness.

Burbank, J. (2014). The rise of the "Sharing" economy. Retrieved from http://www.huffingtonpost.com.au/p/huffpost-australia-about-us

Chatterton, P., \& Pusey, A. (2018). Beyond capitalist enclosure, commodification and alienation: Postcapitalist praxis as commons, social production and useful doing. Progress in Human Geography, 0309132518821173. 
Colling, M. R., Stovall, J., Flaherty, J., Cope, M. R., \& Brown, R. B. (2017). From mass consumer society to a society of consumers: Consumption and the experience of community in late modernity. Community Development, 48(4), 460-482.

Davidson, N. M., \& Infranca, J. J. (2016). The Sharing Economy as an Urban Phenomenon. Yale Law \& Policy Review, 34, 215-279.

Dewsbury, J. D., \& Bissell, D. (2015). Habit geographies: The perilous zones in the life of the individual. Cultural Geographies, 22(1), 21-28.

Diprose, G. (2017). Radical equality, care and labour in a community economy. Gender, Place \& Culture, 24(6), 834-850.

Euler, J. (2018). Conceptualizing the commons: Moving beyond the goods-based definition by introducing the social practices of commoning as vital determinant. Ecological Economics, 143, 10-16.

Foster, S. R. (2011). Collective action and the urban commons. Notre Dame Law Review, $87(1), 57-134$.

Foster, S. R., \& Iaione, C. (2016). The city as a commons. Yale Law \& Policy Review, 34, 281-349.

Frenken, K., \& Schor, J. (2017). Putting the sharing economy into perspective. Environmental Innovation and Societal Transitions, 23, 3-10. doi:10.1016/j.eist.2017.01.003

Friedman, T. L. (2013). Welcome to the 'Sharing Economy'. Sunday Review. Retrieved from http://www.nytimes.com/2013/07/21/opinion/sunday/friedman-welcome-to-thesharing-economy.html

Gibson-Graham, J. K. (1996). The end of capitalism (as we knew it): a feminist critique of political economy. Oxford: Blackwell.

Gibson-Graham, J. K. (2006). A postcapitalist politics. Minneapolis: University of Minnesota Press. 
Gibson-Graham, J. K. (2007). Cultivating subjects for a Community Economy. In A. Tickell, E. Sheppard, J. Peck, \& T. Barnes (Eds.), Politics and practice in economic geography (pp. 106-118). London: Sage.

Gibson-Graham, J. K. (2008). Diverse economies: Performative practices for other worlds'. Progress in Human Geography, 32(5), 613-632.

Gibson-Graham, J. K., Cameron, J., \& Healy, S. (2013). Take back the economy: An ethical guide for transforming our communities. Minneapolis: University of Minnesota Press.

Gibson-Graham, J. K., Cameron, J., \& Healy, S. (2016). Commoning as a postcapitalist politics. In A. Amin \& P. Howell (Eds.), Releasing the commons: Rethinking the futures of the commons (pp. 192). New York: Routledge.

Giorgino, V. M. B. (2018). In search of a new compass in the great transition: Toward codesigning the urban space we care about. In V. M. B. Giorgino \& Z. Walsh (Eds.), Codesigning economies in transition: Radical approaches in dialogue with contemplative social sciences (pp. 15-41). Cham: Palgrave Macmillan.

Gorenflo, N. (2017). Introduction. In Shareable (Ed.), Sharing Cities: Activating the urban commons. Creative Commons Attribution-ShareAlike 4.0 International License (CC BY-SA 4.0): Shareable.

Hardin, G. (1968). The tragedy of the commons. science, 162(3859), 1243-1248.

Harris, E. (2009). Neoliberal subjectivities or a politics of the possible? Reading for difference in alternative food networks. Area, 41(1), 55-63.

Harvey, D. (2005). Neoliberalism: A brief history. Oxford: Oxford University Press.

Heinrichs, H. (2013). Sharing economy: A potential new pathway to sustainability. GAIA, $22(4), 228-231$.

Huron, A. (2015). Working with strangers in saturated space: Reclaiming and maintaining the urban commons. Antipode, 47(4), 963-979. doi:10.1111/anti.12141 
Iaione, C. (2016). The CO-City: Sharing, collaborating, cooperating, and commoning in the city. American Journal of Economics and Sociology, 75(2), 415-455. doi:10.1111/ajes.12145

Kalamar, A. (2013). Sharewashing is the new greenwashing. OpEd News. Retrieved from https://www.opednews.com/articles/Sharewashing-is-the-New-Gr-by-Anthony$\underline{\text { Kalamar-130513-834.html }}$

Klein, N. (2014). This changes everything: Capitalism vs. the climate. New York: Simon and Schuster.

Laverack, G. (2005). Evaluating community capacity: Visual representation and interpretation. Community Development Journal, 41(3), 266-276.

Llewellyn, T. (2016). The complete guide to hosting a \#MapJam in your city. Retrieved from https://www.shareable.net/blog/the-complete-guide-to-hosting-a-mapjam-in-your-city

Llewellyn, T., \& Gorenflo, N. (2016). How to: share, save money and have fun. A shareable guide to sharing. San Francisco: Shareable.

Loh, P., \& Shear, B. (2015). Solidarity economy and community development: Emerging cases in three Massachusetts cities. Community Development, 46(3), 244-260. doi:10.1080/15575330.2015.1021362

Luna, M. (Producer). (2013). Host guide for the sharing cities Map Jam. Retrieved from https://www.shareable.net/blog/host-guide-for-the-sharing-cities-map-jam

Maclurcan, D. (Producer). (2012). How to map assets \& expose real wealth for shared futures. Retrieved from https://www.shareable.net/blog/how-to-map-assets-expose-real$\underline{\text { wealth-for-shared-futures }}$

Manzini, E. (2015). Design, when everybody designs: An introduction to design for social innovation. Massachusetts: MIT press. 
Martiskainen, M. (2017). The role of community leadership in the development of grassroots innovations. Environmental Innovation and Societal Transitions, 22, 78-89.

Mason, P. (2016). Postcapitalism: A guide to our future. New York: Farrar, Straus and Giroux.

Matarrita-Cascante, D., Trejos, B., Qin, H., Joo, D., \& Debner, S. (2017). Conceptualizing community resilience: Revisiting conceptual distinctions. Community Development, $48(1), 105-123$.

May, J., \& Cloke, P. (2014). Modes of attentiveness: Reading for difference in geographies of homelessness. Antipode, 46(4), 894-920.

McFarlane, C. (2011). Assemblage and critical urbanism. City, 15(2), 204-224.

$\mathrm{M}^{\mathrm{c}}$ Guirk, P., \& Dowling, R. (2009). Neoliberal privatisation? Remapping the public and the private in Sydney's masterplanned residential estates. Political Geography, 28(3), 174185.

McLaren, D., \& Agyeman, J. (2015). Sharing cities: A case for truly smart and sustainable cities. London: The MIT Press.

McLaren, D., \& Agyeman, J. (2016). Sharing cities: governing the city as commons. In J. M. Ramos (Ed.), The city as commons: A policy reader (pp. 77-79). Melbourne: Transition Coalition.

McNeill, D., Dowling, R., \& Fagan, B. (2005). Sydney/global/city: An exploration. International Journal of Urban and Regional Research, 29(4), 935-944.

Murillo, D., Buckland, H., \& Val, E. (2017). When the sharing economy becomes neoliberalism on steroids: Unravelling the controversies. Technological Forecasting and Social Change, 125, 66-76. doi:10.1016/j.techfore.2017.05.024

North, P., \& Cato, M. S. (2017). Introduction: New economies North and South - sharing the transition to a just and sustainable future. In P. North \& M. S. Cato (Eds.), Towards 
just and sustainable economies: The social and solidarity economy North and South (pp. 1-35). Bristol: Policy Press.

Olma, S. (2014). Never mind the sharing economy: Here's platform capitalism. Retrieved from http://networkcultures.org/mycreativity/2014/10/16/never-mind-the-sharingeconomy-heres-platform-capitalism/

Ostrom, E. (1990). Governing the commons: The evolution of institutions for collective action. Cambridge: Cambridge University Press.

Piketty, T. (2015). About capital in the twenty-first century. American Economic Review, $105(5), 48-53$.

Probyn, E. (2003). The spatial imperative of subjectivity. In K. Anderson, M. Domosh, S. Pile, \& N. J. Thrift (Eds.), Handbook of cultural geography (pp. 290-299). London: Sage.

Radywyl, N., \& Biggs, C. (2013). Reclaiming the commons for urban transformation. Journal of Cleaner Production, 50(1), 159-170.

Ravenelle, A. J. (2017). Sharing economy workers: Selling, not sharing. Cambridge Journal of Regions, Economy and Society, 10(2), 281-295. doi:10.1093/cjres/rsw043

Rifkin, J. (2014). The zero marginal cost society: The internet of things, the collaborative commons, and the eclipse of capitalism. New York: Palgrave Macmillan.

Rossi, U. (2017). Cities in global capitalism. Cambridge: Taylor \& Francis.

Seyfang, G., \& Smith, A. (2007). Grassroots innovations for sustainable development: Towards a new research and policy agenda. Environmental politics, 16(4), 584-603.

Shareable. (2018). Community maps. Retrieved from https://www.shareable.net/community$\underline{\text { maps }}$

Sharp, D. (2018). Sharing cities for urban transformation: Narrative, policy and practice. Urban Policy and Research, 36(4), 513-526. 
Sharp, D., \& Ramos, J. M. (2018). Design experiments and co-governance for city transitions: Vision Mapping. Journal of Peer Production, January 2018(11).

Srnicek, N. (2017). The challenges of platform capitalism: Understanding the logic of a new business model. Juncture, 23(4), 254-257.

The Economist. (2013). The rise of the sharing economy: On the internet, everything is for hire. Retrieved from https://www.economist.com/news/leaders/21573104-interneteverything-hire-rise-sharing-economy

The Sharing Map. (2018). Retrieved from https://thesharingmap.com.au/

Thorpe, A. (2018). 'This Land is Yours': Ownership and agency in the sharing city. Journal of Law and Society, 45(1), 99-115.

Walsh, Z. (2018). Navigating the great transition via post-capitalism and contemplative social sciences. In V. M. B. Giorgino \& Z. Walsh (Eds.), Co-designing economies in transition (pp. 43-61). Cham: Palgrave Macmillan.

Williams, M. (2018). Urban commons are more-than-property. Geographical Research, 56(1), 16-25. doi:10.1111/1745-5871.12262 